\title{
Uma entrevista com Dawid Surmik: pesquisa e ensino da Paleontologia Molecular
}

\author{
Everton Fernando Alves (1D)
}

Universidade Estadual de Maringá, Museu Dinâmico Interdisciplinar, Avenida Colombo 5790, Jardim Universitário 87020-270, Maringá, Paraná, Brasil. E-mail: efalves.mga@gmail.com

Alves E.F. (2021) Uma entrevista com Dawid Surmik: pesquisa e ensino da Paleontologia Molecular. Pesquisa e Ensino em Ciências Exatas e da Natureza, 5: e1651.

http://dx.doi.org/10.29215/pecen.v5i0.1651

Editor acadêmico: Silvio F. B. Lima. Recebido: 08 fevereiro 2021. Aceito: 12 fevereiro 2021. Publicado: 13 fevereiro 2021.

Resumo: Esta entrevista foi realizada com o tafônomo molecular polonês Dawid Surmik, um dos maiores especialistas em Paleontologia Molecular da atualidade. Surmik nos conta sobre os desafios que despertaram o seu interesse pelo estudo da Paleobiologia de tetrápodes marinhos e terrestres do Mesozóico por meio da aplicação de técnicas inovadoras de detecção de biomoléculas antigas. $\mathrm{Na}$ primeira parte da entrevista, Surmik explica o que é a Paleontologia Molecular, os objetos de estudo, a importância das pesquisas paleomoleculares e as principais técnicas utilizadas em suas investigações. Na segunda parte da entrevista, Surmik apresenta a forma como a Paleontologia Molecular pode ser ensinada para níveis básicos da educação, como no caso do Ensino Fundamental e Médio, e para o Ensino Superior em nível de graduação em Ciências Biológicas. Na última parte, Surmik explora brevemente as possíveis abordagens de investigação da Paleontologia Molecular a partir da perspectiva da Educação em Ciências.

Palavras chave: Ensino de Paleobiologia, Tafonomia Molecular, biomoléculas antigas, educação em ciências.

\section{An interview with Dawid Surmik: research and teaching of Molecular Paleontology}

Abstract: This interview was conducted with the Polish molecular taphonomist Dawid Surmik, one of today's top experts in Molecular Paleontology. Surmik tells us about the challenges that aroused his interest in studying the Paleobiology of Mesozoic marine and terrestrial tetrapods through the application of innovative techniques for detecting ancient biomolecules. In the first part of the interview, Surmik explains what Molecular Paleontology is, the objects of study, the importance of paleomolecular research and the main techniques used in his investigations. In the second part of the interview, Surmik presents how Molecular Paleontology can be taught for basic levels of education, as in the case of elementary and high school, and for higher education at the undergraduate level in Biological Sciences. In the last part, Surmik briefly explores the possible research approaches to Molecular Paleontology from the perspective of Science Education.

Key words: Teaching Paleobiology, Molecular Taphonomy, ancient biomolecules, Science Education.

Dawid Michał Surmik, 35 anos, é um pesquisador polonês, paleontólogo de vertebrados e tafônomo molecular. Possui graduação em Geologia (2008) pela Faculdade de Ciências da Terra da Universidade da Silésia, na Polônia, mestrado em Paleontologia (2010) pela Faculdade de Ciências da Terra da Universidade da Silésia e doutorado GEOBIOS (Paleobiologia Evolutiva) (2014) pelo Instituto de Paleobiologia da Academia Polonesa de Ciências, inclusive, o título de sua tese foi "Microtafonomia de restos de répteis do Triássico Médio da Silésia”. 
Atualmente, Surmik é Professor assistente e membro do Grupo de Pesquisa em Paleoecologia e Tafonomia do Instituto de Ciências da Terra da Faculdade de Ciências Naturais da Universidade da Silésia. Ele constantemente apresenta resultados de suas pesquisas com foco em Paleontologia Molecular para pesquisadores e estudantes como parte de seminários especiais e durante reuniões em eventos científicos.

Surmik participou da preparação de várias exposições em museus, incluindo a concepção e implementação do PaleoSafari Moab Giants em Moab, nos EUA - o primeiro museu icnológico do mundo. Seus interesses científicos se concentram em tetrápodes marinhos e terrestres do Mesozóico Inferior. Surmik é autor e co-autor de dezenas de publicações científicas, incluindo várias no banco de dados Journal Citation Reports.

Desde a infância, Surmik sempre se interessou pela história de nosso planeta, tanto antiga quanto, pelo menos do ponto de vista geológico, não muito distante. Quando era pequeno, ao invés de fazer o que as outras crianças faziam, ele preferia cavar o chão e observar a natureza em busca de conexões e vestígios do passado. Nos primeiros anos do Ensino Fundamental, ele tinha apenas um sonho - queria ser paleontólogo. Surmik afirma que descobrir e descrever organismos pré-históricos, seu modo de vida, reconstruir sua aparência e comportamento é uma grande experiência.

De acordo com Surmik, para descrever como era a vida na Terra há dezenas e centenas de milhões de anos, os paleontólogos estudam os restos de animais completos ou fragmentos de metazoários (principalmente de ossos) que viveram em tempos considerados pré-históricos. Ademais, segundo ele:

\footnotetext{
"Dependendo de seus interesses, os cientistas geralmente procuram indicadores específicos com base nos quais podem reunir informações sobre o estilo de vida e a evolução de espécies que não existem mais hoje. Acontece, entretanto, que um determinado espécime, muitas vezes testado por multidões de especialistas, ainda pode esconder muitos segredos" (Kłoskowicz 2018: 16).
}

Somente nas últimas décadas, tais segredos têm sido revelados pelo progresso que somente a Paleontologia Molecular trouxe para o cenário científico por meio de pesquisadores que ousaram acreditar que havia muito mais dentro dos ossos. Portanto, Surmik trabalha no limite do que é possível. Ele acende nossa imaginação, desvendando segredos bem guardados em vestígios antigos. Por pacientemente e meticulosamente inserir técnicas inovadoras para extrair informações genômicas e proteômicas da pele, dentes e ossos, Surmik tornou-se um dos grandes nomes da pesquisa em Paleontologia Molecular. Desde dinossauros do Cretáceo a répteis marinhos do Triássico - todos sucumbiram ao seu escrutínio.

Dentre suas descobertas, Surmik já encontrou até mesmo ácidos nucléicos (DNA) de répteis datados de aproximadamente 250 milhões de anos (Surmik et al. 2016). Para ele, até agora, ninguém pensava que um material tão antigo pudesse ter preservado vestígios de matéria orgânica primária (Warchala 2016). Esses e outros resultados fazem com que o trabalho de Surmik contribua, de fato, para a expansão do conhecimento convencional da Paleontologia e para a compreensão do processo de evolução em uma escala micro.

Gentilmente, o professor e pesquisador Dawid M. Surmik aceitou participar desta entrevista, via e-mail, no dia 08/02/2021, compartilhando conosco conhecimento não só a respeito de suas pesquisas, mas também sobre perspectivas futuras relativas ao ensino da Paleontologia Molecular.

\section{O que é Paleontologia Molecular e qual é seu objeto de estudo?}

A Paleontologia Molecular ou Tafonomia Molecular é um ramo interdisciplinar da ciência que lida com a preservação de partes moles e especialmente "moléculas fossilizadas", ou seja, compostos orgânicos originais, em fósseis. Essas moléculas podem ser preservadas intactas ou alteradas, mas ainda são identificáveis pelos métodos de, por exemplo, espectroscopia. 
Poucos sabem que a Paleontologia Molecular surgiu com o médico polonês e aclamado pesquisador Professor Roman Pawlicki, aposentado, mas ainda um cientista ativo, que estudou fósseis de vertebrados do deserto de Gobi. Ele foi o primeiro a utilizar métodos moleculares para investigar tecidos moles fossilizados de vertebrados ainda na década de 1960. A paleontóloga norte-americana Dr $^{\mathrm{a}}$ Mary Schweitzer, da Universidade da Carolina do Norte (EUA), baseou seus estudos em métodos desenvolvidos pelo Professor R. Pawlicki.

\section{Em sua opinião, qual a importância da pesquisa em Paleontologia Molecular para a ciência paleontológica do século XXI?}

A identificação de resíduos orgânicos intactos nos aproxima de determinar possíveis posições taxonômicas, relações ou mesmo fisiologia de animais e plantas extintos há muito tempo. Obviamente, os ácidos nucléicos são os mais suscetíveis ao decaimento molecular, mas ainda existem lipídios ou proteínas mais termodinamicamente estáveis, tanto proteínas ou amidas originais quanto fragmentos de aminoácidos. Eles são ocasionalmente encontrados em partes moles fossilizadas - tecidos e células mineralizadas com óxidos de ferro.

As pesquisas têm mostrado, entre outras coisas, que a idade dos fósseis pouco importa quando levamos em conta o estado de preservação da matéria orgânica, pois as condições físicoquímicas em que os fósseis foram fixados se revelaram cruciais. As primeiras horas após a morte do organismo são as mais importantes. Em condições favoráveis, se o material for fixado rapidamente, como aconteceu no caso do material estudado pela minha equipe, ele pode sobreviver em equilíbrio físico-químico 'até o fim do mundo, ou mesmo mais um dia'. Portanto, não importa se examinamos os restos mortais de 80 ou 250 milhões de anos atrás.

A possibilidade de preservar esses compostos orgânicos antigos cria uma oportunidade para pesquisas futuras sobre proteínas fósseis em termos de compreensão do processo de evolução em uma escala micro, e até mesmo para analisar a relação de vários grupos fósseis de vertebrados em nível molecular. É aqui que se abre espaço para pesquisas taxonômicas futuras baseadas em métodos físico-químicos e bioquímicos.

\section{Quais são os métodos e técnicas de trabalho de um paleontólogo molecular?}

Uma decifração aprofundada da biologia de tetrápodes extintos, por exemplo, requer métodos interdisciplinares e sofisticados. Aliás, essa é a tendência contemporânea da pesquisa paleontológica, cada vez mais baseada em análises geoquímicas ou físico-químicas. Junto com o desenvolvimento de campos individuais da ciência, os pesquisadores têm a oportunidade de usar um background cada vez mais rico de métodos analíticos para ter uma visão ainda mais objetiva dos materiais coletados até agora.

Em minha atividade científica, tento combinar a metodologia de pesquisa tradicional, baseada em observações a olho nu de fósseis preservados, com métodos novos e recentes, que permitem o exame da qualidade do registro fóssil. Essa abordagem resultou em várias descobertas importantes, que ampliam nosso conhecimento sobre a preservação de tecidos moles nos restos esqueléticos fossilizados e a identificação de várias doenças que afetam vertebrados extintos. Em cooperação com vários laboratórios, ganhei alguma experiência com as técnicas espectroscópicas mais comuns (espectroscopia de infravermelho com transformada de Fourier, FTIR; espectroscopia Raman; espectroscopia de fotoelétrons de raios-X, XPS), bem como espectrometria de massa de alta resolução (espectrometria de massa de íons secundários por tempo de voo, ToF-SIMS) e técnicas microscópicas (microscopia óptica; microscopia eletrônica de varredura, $\mathrm{MEV})$.

4. Em sua opinião, você acha importante ensinar conceitos gerais de Paleontologia Molecular a alunos de níveis mais básicos, como ensino fundamental e médio? De que forma os professores podem fazer isso?

A meu ver, as disciplinas de ciências, Geografia e Biologia que compõem os currículos da Educação Básica, Ensino Fundamental e Médio, devem trazer elementos que possibilite ao aluno 
entender que o registro fóssil, às vezes, preserva mais do que tecidos duros - ossos e dentes. Isso certamente tornará o currículo mais atraente! Os jovens têm vontade de aprender e, com certeza, cada um gostaria de encontrar DNA de dinossauro.

5. Você acha importante incluir conceitos e temas gerais sobre Paleontologia Molecular para estudantes de nível de graduação em Ciências Biológicas?

Sim, tópicos básicos de Tafonomia Molecular devem ser incluídos nos planos de aula da disciplina de Paleontologia de cursos de graduação em Ciências Biológicas. Este campo de conhecimento inovador e interdisciplinar irá certamente inspirar os alunos a estudar e a preparar interessantes projetos de mestrado! Aliás, o acesso cada vez mais cedo dos alunos à equipamentos de pesquisa mais sofisticados é um fator que favorece esses estudos interdisciplinares.

\section{Como é o ensino de Paleontologia Molecular para alunos de graduação em Ciências Biológicas na Polônia?}

Infelizmente, o ensino de Paleontologia Molecular ainda é limitado a cursos de PósGraduação em Paleontologia ou Paleobiologia, mas esses tópicos têm sido cada vez mais discutidos também durante palestras sobre Tafonomia, seminários departamentais, as chamadas "palestras especiais" ou durante reuniões em eventos científicos.

7. Tenho percebido uma ausência de pesquisas científicas relacionadas ao Ensino da Paleontologia Molecular. Como os pesquisadores da Educação em Ciências podem se aventurar nessa área?

Neste momento, este ainda é um campo da ciência muito hermético (restrito) em todo o mundo, então não é de se estranhar que não se fale muito sobre ele. Acho que uma boa ideia é investir na divulgação científica dos resultados das próprias pesquisas e de terceiros, durante as coletivas e comunicados de imprensa para que o maior número possível de pessoas, incluindo tomadores de decisão, conheça a dimensão da importância de tais pesquisas.

Posso dizer que vejo perspectivas futuras para a realização de novos estudos baseados no Ensino da Paleontologia Molecular, como, entre outros exemplos, a criação de ambientes museológicos nos quais será possível ensinar aos alunos algumas etapas do processo de Tafonomia Molecular, a escrita de livros didáticos, que, aliás, é a melhor forma de se ensinar Paleontologia Molecular e também por meio do desenvolvimento de documentários sobre o assunto.

Além disso, ainda é possível desenvolver, como parte das aulas de laboratório, protocolos mais simplificados para a extração de biomoléculas de fósseis por meio de novos métodos testados. Claro, levando em consideração que o material é muito limitado, mesmo as técnicas analíticas mais sensíveis requerem a quantidade certa de material. Além disso, vale lembrar que parte do material também é perdido no preparo da amostra.

\section{Referências}

Kłoskowicz M. (2018) Paleopatologia. Gazeta Uniwersytecka UŚ, 9(259): 16-17.

Surmik D., Boczarowski A., Balin K., Dulski M., Szade J., Kremer B. \& Pawlicki R. (2016) Spectroscopic Studies on Organic Matter from Triassic Reptile Bones, Upper Silesia, Poland. PLOS ONE, 11(3): e0151143. https://doi.org/10.1371/journal.pone.0151143

Warchala M. (2016) Naukowcy z Uniwersytetu Śląskiego zajrzeli do krwinek triasowych gadów. Magazyn Katowice. Disponível em: https://katowice.wyborcza.pl/katowice/1,35055,19819535,n aukowcy-z-uniwersytetu-slaskiego-zajrzeli-do-krwinek-triasowych.html (Acesso em 03/02/2021 ). 